\title{
Evaluation of the gastrointestinal stromal tumors for clinical features, histopathological findings and prognostic criteria: A case-control study
}

\author{
(1) Tolga Canbak, ${ }^{1}$ () Baris Bayraktar, ${ }^{2}$ (1) Aylin Acar, ${ }^{1}$ () Rafet Yigitbasi ${ }^{3}$ \\ ${ }^{1}$ Department of General Surgery, University of Health Science, Umraniye Training and Research Hospital, Istanbul, Turkey \\ ${ }^{2}$ Department of General Surgery, Gebze Konak Hospital, Gebze, Turkey \\ ${ }^{3}$ Department of General Surgery, Central Hospital, Istanbul, Turkey
}

\begin{abstract}
OBJECTIVE: In this study, we reviewed GISTs with all morphological and immunohistochemical findings and assessed the prognostic parameters of these tumors.

METHODS: Files of 40 cases with GIST operated between 2002 and 2008 were retrospectively examined in this study. Patients were grouped as patients with and without recurrence within postop 1 year. The patients were grouped based on their localization, gender and age. The cases were stratified as the risk grades based on risk categorization table developed by Fletcher et al. according to the tumor diameter and number of mitoses. The cases were immunohistochemically investigated for CD117, CD34, S100, and Ki-67.

RESULTS: Male/female ratio was $25 / 15$. The mean age was 61.55 . Mean tumor diameters were statistically significantly higher in the recurrence $(+)$ group than in the recurrence $(-)$ group $(p=0.048)$. The mean number of mitoses was statistically significantly higher in the recurrence $(+)$ group than in the recurrence $(-)$ group $(p=0.038)$. No statistically significant difference was found in histological distribution of the recurrence $(-)$ and recurrence $(+)$ groups $(p=0.8795)$. No statistically significant difference was found in CD34, S100, and Ki-67 distribution of the recurrence $(-)$ and recurrence $(+)$ groups $(p=0.862$, $p=0.609$, and $p=0.023$, respectively). All patients in the recurrence $(+)$ group were in the high-risk group.

CONCLUSION: GISTs are studied in a wide range from benign, incidental tumors to malignant tumors with the risk for recurrence and metastasis concerning biological behaviour. GISTs have prognostic parameters, such as tumor localization, tumor diameter, mitotic index, cellularity, and pleomorphism grade.
\end{abstract}

Keywords: GIST; interstitial cells of Cajal; Ki-67; mitosis number; recurrence; tumor diameter.

Cite this article as: Canbak T, Bayraktar B, Acar A, Yigitbasi R. Evaluation of the gastrointestinal stromal tumors for clinical features, histopathological findings and prognostic criteria: A case-control study. North Clin Istanb 2020;7(2):161-166.

G astrointestinal stromal tumors (GIST) are mesenchymal tumors with specific histological featuresand are primarily localized in the gastrointestinal system and abdomen. GISTs are a rare tumor group, accounting for less than $1 \%$ of primary gastrointestinal system tumors. It is difficult to predict the clinical behav- iour of GISTs [1]. GISTs may be seen anywhere along the gastrointestinal system, but the most common localizations are the stomach (50-60\%) and small intestine $(20-30 \%)$. These tumors are seen in the large intestine by $10 \%$ and in the esophagus by $5 \%$ [2]. The lesions that cannot be distinguished from GISTs concerning mor-

Received: March 05, 2019 Accepted: May 14, 2019 Online: July 10, 2019

Correspondence: Dr. Tolga CANBAK. Saglik Bilimleri Universitesi, Umraniye Egitim ve Arastirma Hastanesi, Genel Cerrahi Klinigi, Istanbul, Turkey. 
phology and immune phenotype are also described in the localizations other than the gastrointestinal tract, such as the mesentery, omentum, and retroperitoneum [2]. Since omental and mesenteric primary stromal tumors show typical immunohistochemical profile of GISTs, and there are no interstitial cells of Cajal (ICC) in this location. It is thought that GISTs might be developed from the multipotent mesenchymal stem cells (from intestinal mesenchymal precursors) [1]. In general, GISTs are seen after the $4^{\text {th }}$ decade, and the mean age of diagnosis is 60 years. The most common symptoms include upper abdominal pain (50-70\%), gastrointestinal bleeding (20-50\%) and abdominal mass (5\%) [3].

Until recently, GISTs have been classified in the soft tumor sarcomas. They have been classified most commonly in the groups of smooth muscle originated tumors (leiomyosarcoma, leiomyoma, and leiomyoblastoma) and neural crest originated tumors (schwannoma). GIST terminology has been rapidly introduced since 1999.

As histological cell type, GISTs are divided into three groups as spindle type (70\%), epithelioid type (20\%) and rarely seen mixed type. CD117 (kit protein) is detected by $98-100 \%$ almost in all GIST cases [1]. CD34, which is usually associated with hematopoietic and vascular endothelial cells, is seen in 70-80\%, smooth muscle actin (SMA) in 20-40\%, and desmine in a very small portion (1-2\%) of GIST cases, S100 is observed positive in $5 \%[3,4]$.

It is difficult to predict the clinical behaviour of GISTs. Thus, very low risk, low risk, intermediary risk and high-risk definitions have been introduced instead of malignant and benign tumors. The most important and easy to use morphologic criteria used in prediction of tumor behaviour are tumor diameter (maximum tumor diameter in $\mathrm{cm}$ ) and mitotic rate (number of $\mathrm{mi}$ toses/50 BBA) [1, 4].

In this study, were compared and retrospectively examined GIST patients who were operated between 2002 and 2008 in General Surgery clinics concerning clinical features, histopathologic findings and prognostic criteria.

\section{MATERIALS AND METHODS}

Files of 40 patents with GIST operated in general surgical clinics between 2002 and 2008 were retrospectively examined in this study. Informed consent was obtained from all patients. Ethical approval was obtained from the ethics committee of the hospital. Patients were grouped as the patients with and without recurrence within postop 1 year. Twenty-five cases were localized in the stomach, 12 in the small intestine, one case in the rectum, and two cases out of the gastrointestinal tract. Abdominal and peritoneal localized cases were considered as localization out of the gastrointestinal tract. There was no esophageal localized case. Patients were grouped according to their localization, gender, and age. To show biological behaviour of the tumor, risk stratification was made based on the risk categorization table developed by Fletcher et al. according to the tumor diameter and the number of mitoses [5]. The cases were grouped as very low risk, low risk, intermediary risk, and high-risk. The cases were immunohistochemically studied for CD117, CD34, S100, and Ki-67. CD117 and CD34 were evaluated with $(+),(++)$, and $(+++)$ as $<10 \%, 10-50 \%$, and $>50 \%$ based on extensity of the staining. The cases stained $<5 \%$ were considered as negative $(-)$. According to extensity of the staining, S100 stained $<10 \%$ was accepted as negative (-).

Evaluation of the $\mathrm{Ki}-67$ staining pattern was based on the methods used by Furudoi et al., Terlikowski et al. and Dorai. The number of positive cells and total cells were determined in randomly selected three large $40 \mathrm{x}$ magnification areas, and LI (labeling index): Ki-67 LI was calculated with the formula of:

number of positive cells/numbers of total cells x100

for each area, and these three areas were averaged. The cases were divided into three groups as $<1 \%(-), 1-10 \%$ $(+)$, and $>10 \%(++)$. Histological typing included three classes as spindle, epithelioid, and mixed cell. Tumor diameters were stated as centimeter $(\mathrm{cm})$. Mitotic activity as investigated in the patients. Thus, mitoses were counted in large $50 \mathrm{x}$ magnification area [6-8].

\section{Statistical Analysis}

In this study, statistical analysis was carried out using NCSS 2007 software. In evaluation of the data, in addition to the descriptive statistical methods (mean, standard deviation), one way variance analysis in intergroup comparison, independent $t$-test in comparison of two groups, and Chi-square test in comparison of qualitative data. $\mathrm{P}<0.05$ values were considered statistically significant.

\section{RESULTS}

Among the patients diagnosed with GIST, 25 cases $(62.5 \%)$ were localized in the stomach, $12(30 \%)$ in the 
small intestine, $1(2.5 \%)$ in the rectum, and $2(5 \%)$ out of the gastrointestinal tract (omentum, abdominal wall). There was no esophageal localized tumor. Male/female ratio was $25 / 15$. M/F rates by the localizations were $17 / 8$ in the stomach, $6 / 6$ in the small intestine, $2 / 1$ in the other localizations. The mean age was 61.55 (range: 24-85) years (Table 1 ).

Tumor diameters varied between 1 and $24 \mathrm{~cm}$. The mean highest tumor diameter was found in the tumors localized out of gastrointestinal tract, and the mean lowest tumor diameter was found in stomach localized tumors (Table 2). $75 \%$ of the tumors consisted of spindle cells, $5 \%$ epithelioid cells, and $20 \%$ mixed cells (epithelioid and spindle cells. The relationship between localizations and immunohistochemical features is shown in Table 3.

Based on the risk stratification table created by Fletcher et al. in April 2002, 10\% of all patients was in the very low-risk group, $30 \%$ in the low-risk group, $17.5 \%$ in the intermediary risk group, and $42.5 \%$ in the high-risk group [5].

Mean tumor diameters were statistically significantly higher in the recurrence $(+)$ group than in the recurrence $(-)$ group $(p=0.048)$. The mean number of mitoses was statistically significantly higher in the recurrence $(+)$ group than in the recurrence $(-)$ group $(\mathrm{p}=0.038)$ (Table $4)$. There was a statistically significant difference in distribution of the localization between recurrence $(-)$ and recurrence $(+)$ groups $(p=0.0001)$. All patients in the small intestine group developed recurrence. No statistically significant difference was found in the histological distribution of the recurrence $(-)$ and recurrence $(+)$ groups $(\mathrm{p}=0.8795)$. No statistically significant difference was found in pleomorphism distribution of the recurrence $(-)$ and recurrence $(+)$ groups $(\mathrm{p}=0.127)$.

No statistically significant difference was found in CD34, S100, and $\mathrm{Ki}-67$ distribution of the recurrence $(-)$ and recurrence $(+)$ groups $(p=0.862, p=0.609$, and $\mathrm{p}=0.023$, respectively). All patients in the recurrence $(+)$ group were in the high-risk group (Table 5).

\section{DISCUSSION}

GISTs are seen between 8 and 93 years of age, usually after the $4^{\text {th }}$ decade, and at mid-sixties on average [3-5]. Miettinen et al. [9] observed male patient predominance in some case series, while equal distribution has been demonstrated in the other series [3,4]. In our study, the mean age of 40 studied patients was 61.55 years, consis-
TABLE 1. Age relationship with localization

\begin{tabular}{cccccc} 
& $\begin{array}{c}\text { Stomach } \\
(\text { mean } \pm \text { SD })\end{array}$ & $\begin{array}{c}\text { Small intestine } \\
(\text { mean } \pm \text { SD })\end{array}$ & Others & F & p \\
\hline Age & $62.16 \pm 14.77$ & $61.42 \pm 10.33$ & $57 \pm 20.3$ & 0.18 & 0.833 \\
\hline
\end{tabular}

SD: Standard deviation.

TABLE 2. Relationship between localization groups and tumor diameter averages

\begin{tabular}{lccccc} 
& $\begin{array}{c}\text { Stomach } \\
(\text { mean } \pm \text { SD })\end{array}$ & $\begin{array}{c}\text { Small intestine } \\
(\text { mean } \pm \text { SD })\end{array}$ & Other & $F$ & $p$ \\
\hline $\begin{array}{l}\text { Tumor } \\
\text { diameter }\end{array}$ & $7.05 \pm 5.77$ & $8.04 \pm 4.25$ & $9.67 \pm 8.96$ & 0.36 & 0.700 \\
\hline
\end{tabular}

SD: Standard deviation.

TABLE 3. The relationship between localization and immunohistochemical features

$\begin{array}{llcccc} & & \begin{array}{c}\text { Stomach } \\ \%\end{array} & \begin{array}{c}\text { Small intestine } \\ \%\end{array} & \begin{array}{c}\text { Other } \\ \%\end{array} & \\ & & \% & & & \\ & (-) & 12.0 & 8.3 & 66.7 & \\ & (+) & 60.0 & 58.3 & 0.0 & \chi^{2}: 7.72 \\ \text { Ki-67 } & (++) & 28.0 & 33.3 & 33.3 & p=0.102 \\ \text { CD-117 } & (+) & 100.0 & 100.0 & 100.0 & \\ & (-) & 4.0 & 50.0 & 33.3 & \\ & (+) & 36.0 & 25.0 & 33.3 & \\ & (++) & 12.0 & 0.0 & 0.0 & \chi^{2}: 12.08 \\ \text { CD-34 } & (+++) & 48.0 & 25.0 & 33.3 & p=0.064 \\ & (-) & 88.0 & 66.7 & 0.0 & \chi^{2}: \mathbf{1 1 . 7} \\ \text { S-100 } & (+) & 12.0 & 33.3 & 100.0 & p=\mathbf{0 . 0 0 3}\end{array}$

TABLE 4. Tumor diameter and mitosis number meanings of recurrent groups

\begin{tabular}{lcccc} 
& $\begin{array}{c}\text { Recurrence }(-) \\
(\text { mean } \pm \text { SD })\end{array}$ & $\begin{array}{c}\text { Recurrence }(+) \\
(\text { mean } \pm S D)\end{array}$ & $t$ & $p$ \\
\hline $\begin{array}{l}\text { Tumor diameter } \\
(\mathrm{cm})\end{array}$ & $6.83 \pm 5.56$ & $11.58 \pm 2.97$ & -2.03 & $\mathbf{0 . 0 4 8}$ \\
Mitosis number & $5.71 \pm 12.65$ & $18.5 \pm 17.9$ & -2.15 & $\mathbf{0 . 0 3 8}$
\end{tabular}

SD: Standard deviation. 
TABLE 5. Distribution of the recurrence groups by risk groups

$\begin{array}{cc}\text { Recurrence (-) } & \text { Recurrence (+) } \\ \% & \%\end{array}$

Risk

$\begin{array}{lccc}\text { Very low risk } & 11.8 & 0.0 & \\ \text { Low risk } & 35.3 & 0.0 & \\ \text { Moderate risk } & 20.6 & 0.0 & \chi^{2}: \mathbf{9 . 5 5} \\ \text { High-risk } & 32.4 & 100.0 & \mathrm{p}=\mathbf{0 . 0 2 3}\end{array}$

tent with the literature. The highest mean age was found in the stomach localized GISTs. No significant correlation was found between the age of diagnosis, localization, and recurrence groups. Evaluating the patients by gender, $62.5 \%$ patients were male, and $37.5 \%$ patients female. These ratios reflected the higher male patient predominance in the literature. No significant correlation was found between gender, localization, and recurrence groups.

The prediction of malignant behaviour of GISTs is often difficult. Various factors have been studied in the estimation of prognosis. These factors include a mitotic index, growth pattern, tumor size, telomerase activity, proliferation determinants, localization, flow cytometry, hemorrhage, necrosis, and cellularity [10-13]. Among these, mitotic index and tumor diameter are of special importance. Fletcher et al. recommended the use of risk assessment instead of distinguishing as benign and malignant with sharp margins [5]. In our study, we stated that GIST cases should be divided into four risk groups based on mitosis and tumor diameter. Researchers have emphasized that all GISTs have malignancy potential. Thus, the benign term should not be used [5]. This approach was approved by the American National Health Institute in 2001. Later Nakamura et al. [14] found correlation between clinical outcomes based on patient follow-up with risk stratification system in 80 patients they followed-up. In our study, tumor diameter and mitosis number parameters that we used to create the risk groups were correlated with recurrence. All patients who developed recurrence were in the high-risk group. There was a significant correlation between histological risk groups and recurrence. These results support the parallelism between risk groups and clinical outcomes.

In AFIP series of 1004 cases, $52 \%$ of GISTs were localized in the stomach, $25 \%$ in the small intestine, $10 \%$ in the rectum/colon, $6 \%$ in the omentum/mesentery, and $5 \%$ in the esophagus [15]. Several studies have found a significant relationship between localization and clinical outcomes [12, 13, 15]. Emory et al. [15] reported that survival was the worst in small intestine tumors and the best in esophageal tumors. In the same study, it was underlined that tumor localization was a prognostic marker independent from age, mitotic rate, and tumor size. In their series of 80 cases, Nakamura et al. [14] found no significant difference in survival analysis of stomach localization tumors and non-stomach localized tumors. In our study, the most common localization was the stomach $(62.5 \%)$, followed by the small intestine (30\%). We found no significant difference between tumor localization and histological risk groups, however localization as statistically significantly associated with recurrence. All cases with recurrence were small intestine localized. No significant difference was found between localization and tumor diameter.

Many studies have reported an association between tumor diameters and malignancy in GISTs $[11,13,16]$. In their study on 1765 patients with stomach localized GIST who were followed up for 5 to 33 years, Miettinen et al. reported that surprisingly tumors $>10 \mathrm{~cm}$ with low mitotic activity were of relatively good prognosis, metastasis occurred in only $12 \%$ of these case after $5-15$ years of follow-up [17]. Thus, malignant label should not be given just because large tumor sizes [17]. The mean tumor diameter was $11.58 \mathrm{~cm}$ in the recurrent cases. Tumor size $>10 \mathrm{~cm}$ in these patients is consistent with the literature, indicating a correlation between tumor diameter and malignant behaviour.

Mitosis is an important prognostic marker. Various studies have a correlation between mitosis and malignancy $[5,12,13,15]$. In our study, the number of mitoses was statistically significantly higher in the recurrence $(+)$ group than in the recurrence $(-)$ group. This finding shows that mitosis is associated with malignant behaviour.

Miettinen et al. [18] reported that epithelioid and mixed tumors have a worse prognosis compared to spindle cell tumors, while Fujimoto et al. stated that presence of epithelioid components indicates a poor prognosis [19]. In their study on 39 patients with the jejunum and ileum originated GISTs, Brainard et al. reported that the epithelioid component is a malignity finding in the small intestine tumors [20]. Tazawa et al. [13] found no correlation between the cellular type 
and tumor aggressiveness. In our study, the patients were grouped based on the dominant cell type, and no correlation was found between the cellular type and recurrence $(+)$ and recurrence $(-)$ groups, and also no association was seen between localization and histology. We thought that the dominant cell type is not of prognostic value.

Brainard et al. reported pleomorphism as a poor prognostic value [20]. Wang et al, reported that pleomorphism is associated with malignant behaviour [12]. Tazawa et al. [13] reported no correlation between pleomorphism and aggressive behaviour of the tumor, while Miettinen et al. stated that the importance of pleomorphism is not clear in GIST [21]. Likewise, in our study, we found no statistically significant difference between the pleomorphism distributions of the recurrence $(+)$ and recurrence $(-)$ groups, and it was thought to be not associated with malignant behaviour. In addition, no significant difference was observed between localization and pleomorphism distribution.

Various studies have found C-kit positivity in varying rates in GISTs [22, 23]. Hirota et al. [23] reported C-kit expression in 94\% of GIST cases. Kindblom et al. found positive staining by $100 \%$. Sircar et al. reported losses in C-kit and CD34 expression in malignant cases [24]. Tazawa et al. [23] found a correlation between Ckit negativity and malignant potential. In our study, we found positive staining by $100 \%$. C-kit staining found as $100 \%$ indicated once again that C-kit is an essential marker of GIST diagnosis.

CD34 is a surface glycoprotein, which has been detected in vascular endothelium, hemopoietic progenitor cells, and some mesenchymal tumors [25, 26]. CD34 is also positive in the interstitial cells of Cajal (ICC) and GISTs $[22,23,27]$. Several studies have found positive staining by $72-78 \%[22,23]$. Miettinen et al. [28] reported that CD34 expression changed by localization, and the highest expression was found in the esophagus and rectum. In the same study, no significant difference was found between the malignant and benign cases concerning CD34 expression. In our study, CD34 expression was found in $80 \%$ of all cases. No statistically significant association was found between localization and CD34 expression. No significant correlation was found between the extensity of CD34 staining and histological risk groups. CD34 staining found commonly in GISTs indicated that this market might be helpful for the diagnosis in the case of C-kit negativity.
Positivity with S100 has been found in $6-28 \%$ of GISTs [11, 13]. Hasegawa et al. [29] reported the most common expression of S100 in the small intestine. Miettinen et al. [28] found positivity in $15 \%$ of the small intestine tumors and reported cytoplasmic and nuclear extensity of staining as 10-100\% . In a study in the literature, strong-to-moderate staining was obtained in 37\% $(13 / 35)$ of the 35 GIST cases, and S100 positive group was reported to have a tendency to a worse prognosis and higher recurrence [30]. In our study, we found a $25 \%$ positivity, and the stomach localized GISTs were statistically significantly less stained compared to the non-stomach localized ones. No significant correlation was found between the extensity of S100 staining, histological risk groups and recurrence groups.

There are many studies in the literature reporting that $\mathrm{Ki}-67$ index is a simple, reproducible, and reliable method in obtaining information about the proliferative capacity of the tumor. Increased expression of $\mathrm{Ki}-67$ is associated with malignant behaviour of the tumor $[31,32]$. Wang et al. reported that $\mathrm{Ki}-67$ is a marker independent from the mitotic index, tumor size, localization, hemorrhage, and necrosis [33]. In our study, we evaluated the effectiveness of $\mathrm{Ki}-67$ in the prediction of malignant potential. A Ki67 index over 10\% was not found in any histopathological low-risk group and $83.3 \%$ of the $\mathrm{Ki}-67(++)$ group was in the high and moderate risk groups. However, a significant correlation could be revealed between the $\mathrm{Ki}$ 67 index and histological risk groups, the number of mitoses, and recurrence groups. The limitation of this study is that patients evaluated retrospectively.

\section{Conclusion}

Morphologic and immunohistochemical investigations take an important place for a correct diagnosis, classifcation, prognosis and treatment. GISTs are studied in a wide range from benign, incidental tumors to malignant tumors with the risk for recurrence and metastasis concerning biological behaviour. Therefore, the ability to determine the behaviour in advance is of importance. They have prognostic parameters, such as tumor diameter, mitotic index, cellularity, and pleomorphism grade. In the literature, studies with day-to-day increasing number try to predict many other determinants in order to determine clinical behaviour and prognostic parameters. In the present study, GISTs were reviewed with all morphological and immunohistochemical findings and their prognostic parameters were evaluated. 
Ethics Committee Approval: Ethical approval was obtained from the Istanbul Goztepe Training and Research Hospital Drug Research Ethics Committee (date: 02.06.2009; number: 57/GC1).

Conflict of Interest: No conflict of interest was declared by the authors.

Financial Disclosure: The authors declared that this study has received no financial support.

Authorship Contributions: Concept - TC, RY, BB; Design - TC, RY, BB; Supervision - TC, RY, BB, AA; Fundings - TC, RY, BB, AA; Materials - TC, BB; Data collection and/or processing - TC; Analysis and/or interpretation - TC, RY, BB; Literature review - TC, RY, BB, AA; Writing - TC, AA, RY, BB; Critical review - TC, AA.

\section{REFERENCES}

1. Duffaud F, Blay JY. Gastrointestinal stromal tumors: biology and treatment. Oncology 2003;65:187-97. [CrossRef]

2. Dei Tos AP. The reappraisal of gastrointestinal stromal tumors: from Stout to the KIT revolution. Virchows Arch 2003;442:421-8. [CrossRef]

3. Sturgeon C, Chejfec G, Espat NJ. Gastrointestinal stromal tumors: a spectrum of disease. Surg Oncol 2003;12:21-6. [CrossRef]

4. Connolly EM, Gaffney E, Reynolds JV. Gastrointestinal stromal tumours. Br J Surg. 2003;90(10):1178-86. [CrossRef]

5. Fletcher CD, Berman JJ, Corless C, Gorstein F, Lasota J, Longley BJ, et al. Diagnosis of gastrointestinal stromal tumors: A consensus approach. Hum Pathol 2002;33:459-65. [CrossRef]

6. Furudoi A, Tanaka S, Haruma K, Yoshihara M, Sumii K, Kajiyama G, et al. Clinical significance of human erythrocyte glucose transporter 1 expression at the deepest invasive site of advanced colorectal carcinoma. Oncology 2001;60:162-9. [CrossRef]

7. Terlikowski S, Sulkowski S, Lenczewski A, Musiatowicz B, Kulikowski M. Study of borderline and invasive mucinous ovarian tumors using $\mathrm{Ki}$ 67 (MIB 1) antibodies and nucleolar organizer region (NOR) staining. Arch Gynecol Obstet 1999;263:29-33. [CrossRef]

8. Darai E, Walker-Combrouze F, Dauge-Geoffroy MC, Vincent Y, Feldmann G, Madelenat P, et al. Ki 67 expression in 35 borderline ovarian tumours: relations with clinicopathologic parameters and ploidy. Eur J Obstet Gynecol Reprod Biol 1998;76:175-80. [CrossRef]

9. Miettinen M, Sarlomo-Rikala M, Lasota J. Gastrointestinal stromal tumours. Ann Chir Gynaecol 1998;87:278-81.

10. Rudolph P, Chiaravalli AM, Pauser U, Oschlies I, Hillemans M, Gobbo $\mathrm{M}$, et al. Gastrointestinal mesenchymal tumors-immunophenotypic classification and survial analysis. Virchows Arch 2002;441:238-48.

11. Rudolph P, Chiaravalli AM, Pauser U, Oschlies I, Hillemanns M, Gobbo $\mathrm{M}$, et al. Gastrointestinal mesenchymal tumors - immunophenotypic classification and survival analysis. Virchows Arch 2002;441:238-48.

12. Wang X, Mori I, Tang W, Utsunomiya H, Nakamura M, Nakamura Y, et al. Gastrointestinal stromal tumors: clinicopathological study of Chinese cases. Pathol Int 2001;51:701-6. [CrossRef]

13. Tazawa K, Tsukada K, Makuuchi H, Tsutsumi Y. An immunohistochemical and clinicopathological study of gastrointestinal stromal tumors. Pathol Int 1999;49:786-98. [CrossRef]

14. Nakamura N, Yamamoto H, Yao T, Oda Y, Nishiyama K, Imamura M, Yamada T, Nawata H, Tsuneyoshi M. Prognostic significance of expressions of cell-cycle regulatory proteins in gastrointestinal stromal tumor and the relevance of the risk grade. Hum Pathol 2006;37:503.

15. Emory TS, Sobin LH, Lukes L, Lee DH, O'Leary TJ. Prognosis of gastrointestinal smooth-muscle (stromal) tumors: dependence on anatomic site. Am J Surg Pathol 1999;23:82-7. [CrossRef]

16. Carrillo R, Candia A, Rodriguez-Peralto JL, Caz V. Prognostic significance of DNA ploidy and proliferative index (MIB-1 index) in gastrointestinal stromal tumors. Hum Pathol 1997;28:160-5. [CrossRef]

17. Miettinen M, Sobin LH, Lasota J. Gastrointestinal stromal tumors of the stomach: a clinicopathologic, immunohistochemical, and molecular genetic study of 1765 cases with long-term follow-up. Am J Surg Pathol 2005;29:52-68. [CrossRef]

18. Miettinen M, Makhlouf H, Sobin LH, Lasota J. Gastrointestinal stromal tumors of the jejunum and ileum: a clinicopathologic, immunohistochemical, and molecular genetic study of 906 cases before imatinib with long-term follow-up. Am J Surg Pathol 2006;30:477-89. [CrossRef]

19. Fujimoto Y, Nakanishi Y, Yoshimura K, Shimoda T. Clinicopathologic study of primary malignant gastrointestinal stromal tumor of the stomach, with special reference to prognostic factors: analysis of results in 140 surgically resected patients. Gastric Cancer 2003;6:39-48. [CrossRef]

20. Brainard JA, Goldblum JR. Stromal tumors of the jejunum and ileum: a clinicopathologic study of 39 cases. Am J Surg Pathol 1997;21:407-16.

21. Miettinen M, El-Rifai W, H L Sobin L, Lasota J. Evaluation of malignancy and prognosis of gastrointestinal stromal tumors: a review. Hum Pathol 2002;33:478-83. [CrossRef]

22. Kindblom LG, Remotti HE, Aldenborg F, Meis-Kindblom JM. Gastrointestinal pacemaker cell tumor (GIPACT): gastrointestinal stromal tumors show phenotypic characteristics of the interstitial cells of Cajal. Am J Pathol 1998;152:1259-69.

23. Hirota S, Isozaki K, Moriyama Y, Hashimoto K, Nishida T, Ishiguro $\mathrm{S}$, et al. Gain-of-function mutations of $\mathrm{c}$-kit in human gastrointestinal stromal tumors. Science 1998;279:577-80. [CrossRef]

24. Sircar K, Hewlett BR, Huizinga JD, Chorneyko K, Berezin I, Riddell $\mathrm{RH}$. Interstitial cells of Cajal as precursors of gastrointestinal stromal tumors. Am J Surg Pathol 1999;23:377-89. [CrossRef]

25. Rosai J. Rosai and Ackerman's Surgical Pathology. $9^{\text {th }}$ ed. China: Elsevier Inc; 2004.

26. Nickoloff BJ. The human progenitor cell antigen (CD34) is localized on endothelial cells, dermal dendritic cells, and perifollicular cells in formalin-fixed normal skin, and on proliferating endothelial cells and stromal spindle-shaped cells in Kaposi's sarcoma. Arch Dermatol 1991;127:523-9. [CrossRef]

27. Hirota S. Gastrointestinal stromal tumors: their origin and cause. Int J Clin Oncol 2001;6:1-5. [CrossRef]

28. Miettinen M, Sobin LH, Sarlomo-Rikala M. Immunohistochemical spectrum of GISTs at different sites and their differential diagnosis with a reference to CD117 (KIT). Mod Pathol 2000;13:1134-42. [CrossRef]

29. Hasegawa T, Matsuno Y, Shimoda T, Hirohashi S. Gastrointestinal stromal tumor: consistent CD117 immunostaining for diagnosis, and prognostic classification based on tumor size and MIB-1 grade. Hum Pathol 2002;33:669-76. [CrossRef]

30. Perez D, Demartines N, Meier K, Clavien PA, Jungbluth A, Jaeger D. Protein S100 as prognostic marker for gastrointestinal stromal tumors: a clinicopathological risk factor analysis. J Invest Surg 2007;20:181-6.

31. Noguchi T, Sato T, Takeno S, Uchida Y, Kashima K, Yokoyama S, et al. Biological analysis of gastrointestinal stromal tumors. Oncol Rep 2002;9:1277-82. [CrossRef]

32. Prenen H, Cools J, Mentens N, Folens C, Sciot R, Schöffski P, et al. Efficacy of the kinase inhibitor SU11248 against gastrointestinal stromal tumor mutants refractory to imatinib mesylate. Clin Cancer Res 2006;12:2622-7. [CrossRef]

33. Wang X, Mori I, Tang W, Utsunomiya H, Nakamura M, Nakamura Y, Zhou G, Kakudo K. Gastrointestinal stromal tumors: clinicopathological study of Chinese cases. Pathol Int 2001;51:701-6. [CrossRef] 